\title{
Oestrogen receptor analysis: Correlation between enzyme immunoassay and immunohistochemical methods
}

\author{
T A Aasmundstad, O A Haugen, E Johannesen A L Høe, S Kvinnsland
}

\begin{abstract}
Aims: To compare oestrogen receptor measurements on fresh tissue done by an enzyme immunoassay (ER-EIA, Abbott) and an immunohistochemical technique (ER-ICA, Abbott) using formalin fixed, parafiin wax embedded material.

Methods: The ER-EIA is based on a sandwich immunoassay using fresh frozen tissue, and the absorbence values were read by a Quantum Analyzer. Sections were cut from the corresponding paraffin wax blocks, and after pretreatment with pronase and DNase, the slides were incubated with monoclonal oestrogen antibody. The immunoperoxidase staining was scored semiquantitatively, incorporating both the intensity and percentage of positive staining (HSCORE).

Results: HSCORE rating of the ER-ICA slides gave a significant correlation with the quantitative ER-EIA values $(r=0.76$; $p<0.001)$. The overall sensitivity and specificity of the immunohistochemical method was $88 \%$ and $93 \%$, respectively.

Conclusions: ER-ICA on routinely processed material can be a valuable alternative when biochemical analysis of oestrogen receptor content is not available. Furthermore, immunohistochemical staining identifies oestrogen receptor positivity at a cellular level, which ensures that the analysed material is representative. This technique could therefore be particularly valuable in small tumours and in situ lesions.
\end{abstract}

Oestrogen receptor analysis is widely used in the management of breast and endometrial cancers. The main interest in oestrogen receptor content is because of its ability to predict the response to endocrine treatment ${ }^{1}$ and its possible value as an overall prognostic indicator ${ }^{23}$ in breast and endometrial cancers.

Various biochemical analyses have been used routinely for oestrogen receptor quantification, ${ }^{4}$ and despite their known clinical value, these assays have some disadvantages. In general, these methods indicate either the steroid binding capacity or number of femtomoles of oestrogen receptor per unit weight of tissue protein, but they cannot identify the cellular origin of the receptors, and fresh or freshfrozen tissue is an absolute prerequisite. Furthermore, breast cancer tumours often contain large and variable amounts of protein-rich connective tissue which increases the risk of error. The amount of material needed for adequate biochemical analysis usually exceeds what is available in many early lesions. Finally, because it is consumed during the assay, tissue for analysis cannot be completely verified by histological examination as containing representative cells.

These obstacles can be overcome to a large extent by using monoclonal antibodies against oestrogen receptors on histological sections, where tumour positivity can be identified at a cellular level, and to exclude the influence of variance of tumour tissue cellularity.

Immunohistochemical oestrogen receptor staining in frozen sections has been compared with various biochemical assays, and its validity confirmed in several studies. ${ }^{5}$ Immunocytochemical detection of oestrogen and progesterone receptors in frozen sections has recently been shown to correlate with tumour grade and menopausal status, and furthermore, to be a better predictor of prognosis than biochemical steroid receptor analysis. Oestrogen receptor immunostaining on paraffin wax embedded sections has the advantage of better cytomorphological preservation, and permits assessment of larger sections as well as retrospective analysis. In a limited number of tumours from these reported studies $^{5}$ there was generally good agreement between the ER-ICA and the dextran coated charcoal assays. We are not aware of any reports, however, that compare ER-ICA on paraffin wax sections with an enzyme immunoassay. The purpose of the present study, therefore, was to compare an enzyme immunoassay (ER-EIA, Abbott) using fresh tissue with an immunohistochemical technique (ER-ICA, Abbott) for oestrogen receptor measurement in various breast and uterine lesions using standard formalin fixed and paraffin wax embedded material from the same cases.

\section{Methods}

TISSUES

The first 15 cases of breast or uterine lesions with enzyme immunoassay values of $<10 \mathrm{fmol} /$ $\mathrm{mg}, 11-50 \mathrm{fmol} / \mathrm{mg}, 51-100 \mathrm{fmol} / \mathrm{mg}$ and $>100 \mathrm{fmol} / \mathrm{mg}$, respectively, and in which the histopathological examination of the surgical specimen had been done in our department, were selected. In three cases the formalin fixed and paraffin embedded tissue was either miss- 

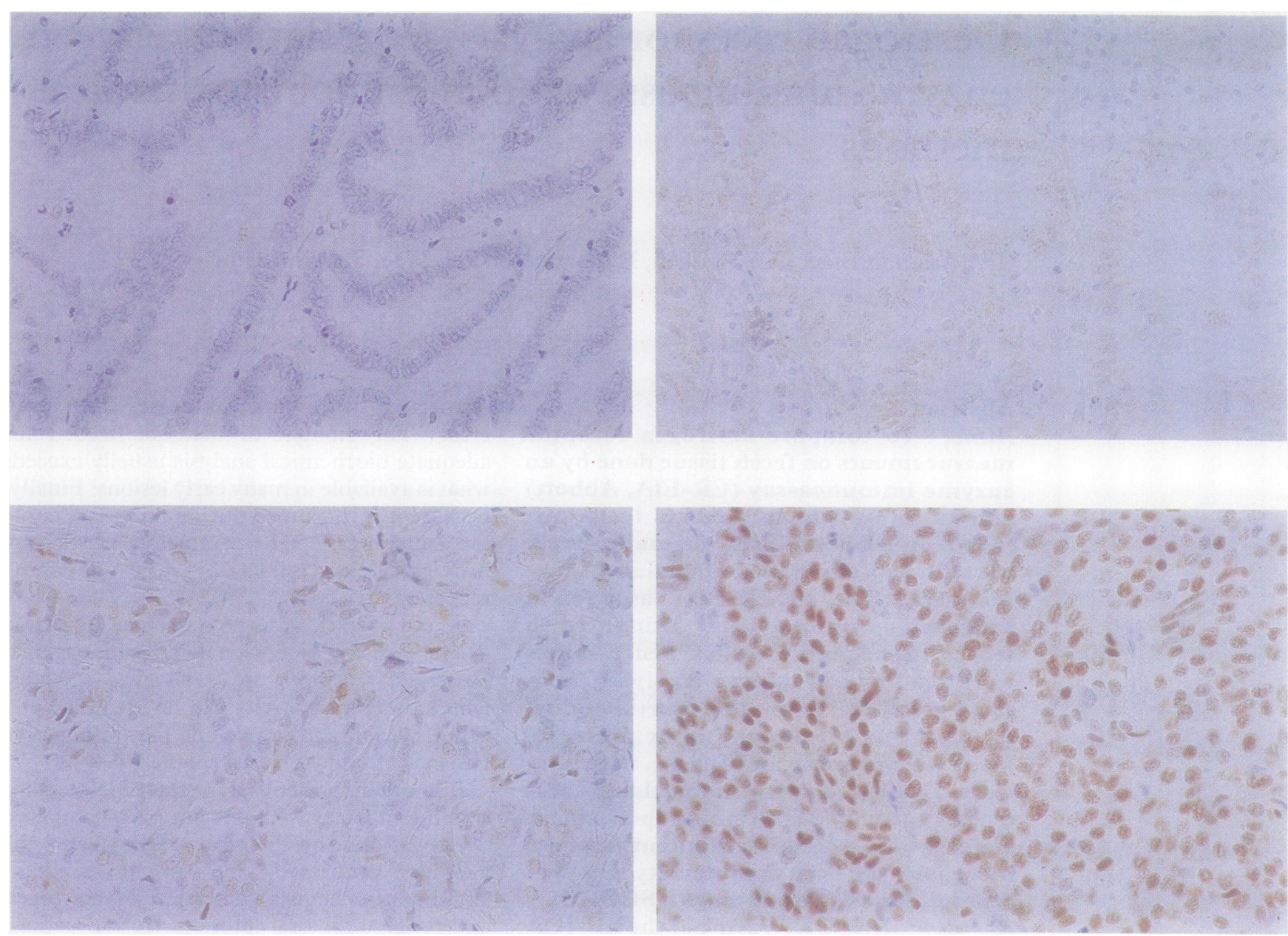

Figure 1 Oestrogen receptor ICA staining in $(A)$ moderately well differentiated (grade 2 ) endometrial carcinoma, oestrogen receptor EIA = $441 \mathrm{fmol} / \mathrm{mg}, H S C O R E=0$, (false negative HSCORE); (B) well differentiated (grade 1) endometrial carcinoma oestrogen receptor EIA $=$ $502 \mathrm{fmol} / \mathrm{mg}, \mathrm{HSCORE}=245 ;(\mathrm{C})$ invasive mammary carcinoma of ductal type, oestrogen receptor EIA $=776 \mathrm{fmol} / \mathrm{mg}, \mathrm{HSCORE}=270 . \mathrm{Note}$ the heterogeneity of oestrogen receptor positivity among the malignant cells. (D) Invasive mammary carcinoma of ductal type, oestrogen receptor EIA $=816 \mathrm{fmol} / \mathrm{mg}, \mathrm{HSCORE}=320$.

ing (one case) or too scanty, so the study included 32 breast lesions and 25 endometrial carcinomas.

All reagents used in both the enzyme immunoassay and the immunoperoxidase procedure were obtained commercially as kits from Abbott laboratories (Chicago, Illinois, USA).

\section{ENZYME IMMUNOASSAY}

Frozen portions of tumours were sent to the Department of Oncology for oestrogen receptor analysis by the ER-EIA (Abbott). The absorbence assay values were read by a Quantum Analyzer, and the receptor values were reported as the number of femtomoles of oestrogen receptor per milligram of cytosol protein. Values of less than $10 \mathrm{fmol} / \mathrm{mg}$ were considered negative. The interassay coefficient of variation $(\mathrm{CV})$ was $6.0 \%$ and intra-assay $\mathrm{CV}$ was $8.3 \%$.

PREPARATION AND STAINING OF PARAFFIN WAX SECTIONS

The material was fixed in $10 \%$ neutral buffered formalin solution at room temperature for about 12 to $\mathbf{4 8}$ hours and processed for routine wax embedding. Sections were cut at $4 \mu \mathrm{m}$ and placed on poly-L-lysine coated slides, dried at $37^{\circ} \mathrm{C}$ overnight, dewaxed in xylene, passed through graded alcohols, and rinsed in phosphate buffered saline (PBS), $\mathrm{pH} 7 \cdot 3$, at $22^{\circ} \mathrm{C}$ ). The sections were then treated according to a procedure developed in our laboratory based on a combination of the methods published by Shintaku and Said ${ }^{6}$ and Cheng et al. ${ }^{7}$ Briefly, sections were covered with several drops of Pronase (Calbiochem-Behring Corporation, La Jolla, California, USA) $5 \mathrm{mg} / \mathrm{ml}$ of PBS, pH $7 \cdot 3$, at $22^{\circ} \mathrm{C}$. Sections from endometrial carcinomas and mammary lesions were incubated in a humidity chamber for five and 10 minutes, respectively. Sections were then rinsed twice in $0.05 \mathrm{M}$ TRIS buffer ( $\mathrm{pH} 7.6$ at $22^{\circ} \mathrm{C}$ ) for five minutes before they were covered with several drops of a DNase I (\# D-5025 type IV, Sigma, St Louis, Missouri, USA) solution $(5 \mathrm{mg} / \mathrm{ml}$ $0.05 \mathrm{M}$ TRIS buffer, $\mathrm{pH} 7.6$, at $22^{\circ} \mathrm{C}$ containing $0.02 \mathrm{M} \mathrm{MgSO}_{4}$ ), and incubated in a humidity chamber for 30 minutes at room temperature. Sections were rinsed in PBS, incubated with blocking reagent (normal goat serum in PBS with antimicrobial agent) for 15 minutes, and then incubated overnight at room temperature with several drops of primary antibody diluted 1 in 1 in PBS with $1.5 \%$ Tween 20 (Sigma). After a rinse in PBS sections were successively incubated for 60 
minutes in bridging antibody and the peroxidase-antiperoxidase complex and then incubated in the chromogen substrate solution (DAB) for 10 minutes. Sections were then washed in tap water, lightly counterstained with Harris's hematoxylin, dehydrated, cleared and mounted. Negative control slides were incubated with the control antibody (normal rat antibody) included in the kit. Sections of known oestrogen receptor positive tumours were included with each run. The interassay coefficient of variation (CV) was $7 \cdot 9 \%$.

\section{INTERPRETATION OF IMMUNOPEROXIDASE \\ STAINING}

All sections were initially read independently by two of the authors (TAa and OAH). The scores were then compared, and a final score was agreed after simultaneous viewing of slides by both observers on a dual headed microscope. Staining was rated semiquantitatively, incorporating both the intensity and distribution of specific staining as described by McCarty et al. ${ }^{8}$ The estimated percentage of neoplastic cells with positive nuclear staining in each of four categories was recorded. The staining intensity was graded as follows: $0=$ no staining; 1 = weak staining; $2=$ moderate staining; 3 = strong staining. These percentages, designated as $\mathrm{P} 1, \mathrm{P} 2$, and $\mathrm{P} 3$ were used in the following calculation. A value was derived consisting of a sum of these percentages multiplied by a weighted intensity of staining. This histochemical score $(\mathrm{HSCORE})=\Sigma(\mathrm{i}+1) \mathrm{P}_{1}$, where $i=1,2,3$, and $P_{i}$ varies from $0 \%$ to $100 \%$. Cells were designated oestrogen receptor positive when there was distinct brown granular nuclear staining with the oestrogen receptor antibody. A tumour was considered "negative for oestrogen receptor" if none of the neoplastic cells had any nuclear staining, and "positive for oestrogen receptor" if any percentage of neoplastic cells stained (fig 1).

The significance of the difference between ER-EIA and ER-ICA was determined by standard $\chi^{2}$ analysis. The correlation of the biochemical results and the immunohistochemical scores was tested by regression analysis.

\section{Results}

STAINING PATTERN

Positive staining was restricted to the nuclei of epithelial cells in the breast lesions; in sections from the uterus positive staining was observed in the nuclei of both epithelial and stromal cells. The proportion of positive cells ranged from $0-90 \%$. Considerable heterogeneity was observed with respect to the intensity of nuclear staining in individual cells within the same section. Normal cellular elements showed nuclear oestrogen receptor staining in sections from both oestrogen receptor positive and oestrogen receptor negative tumours, and served as internal controls when present. There was no staining of cell nuclei in the negative control slides. Intraobserver variation is shown in fig 2. This plot shows the HSCORE generated in the first and second review of the slides by observer I. There was a high correlation between the first and second review $(r=0.97 ; p$ $<0.0001)$. Interobserver variation is shown in fig 3. This plot shows the HSCORE generated in the first review by observer I with the second observer. The graph shows a close correlation with an $r$ value of $0.95(p<0.0001)$.

COMPARISON OF ENZYME IMMUNOASSAY WITH HISTOCHEMICAL OESTROGEN RECEPTOR ANALYSES The histochemical score agreed with the enzyme immunoassay in 51 of 57 cases $(89 \%)$ (table). The correlation coefficient relating HSCORE to EIA values was 0.76 ( $p<0.001$ ) (fig 4). In one case of fibroadenomatosis with an EIA value of $6 \mathrm{fmol} / \mathrm{mg}$, there was scattered weak positive staining of the nuclei in $15 \%$ of the epithelial cells, yielding an HSCORE of 30. Five cases that came out negative with the ICA technique had EIA values above $10 \mathrm{fmol} / \mathrm{mg}$. This group consisted of one fibroadenoma, one invasive breast carcinoma of ductal type, and two moderately (grade 2) and one well differentiated (grade 1) endometrial adenocarcinoma with EIA values of $11,56,29,441$ (fig 1) and $16 \mathrm{fmol} / \mathrm{mg}$, respectively. Using the EIA ER value as the reference value, this resulted in an overall sensitivity of $88 \%$ and an overall specificity of $93 \%$ (table).

\section{Discussion}

Monoclonal antibodies directed against oestrogen receptors have facilitated the development of immunohistochemical techniques for the assessment of oestrogen receptor content. ${ }^{9}$ This is particularly interesting in breast and endometrial carcinomas, where knowledge of the oestrogen receptor content is used to predict outcome and to influence therapeutic strategy. ${ }^{1-3}$ This information has previously been obtained by various biochemical methods. The data presented in our study indicate a significant correlation between an immunohistochemical method and a quantitative enzyme immunoassay. The oestrogen receptor ICA kit from Abbott containing the rat monoclonal H222 SP raised against MCF-7 human breast cancer oestrogen receptor protein ${ }^{9}$ is used for the detection of oestrogen receptor in

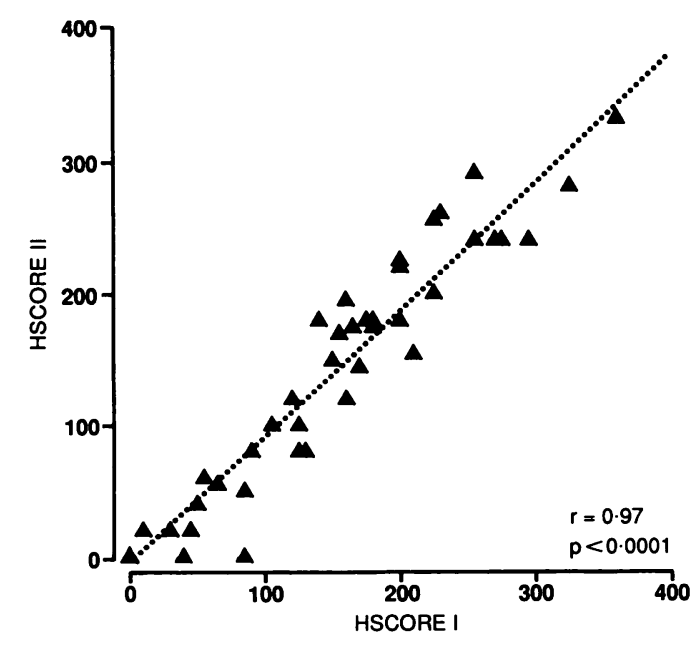

Figure 2 Intraobserver variation (observer 1). 


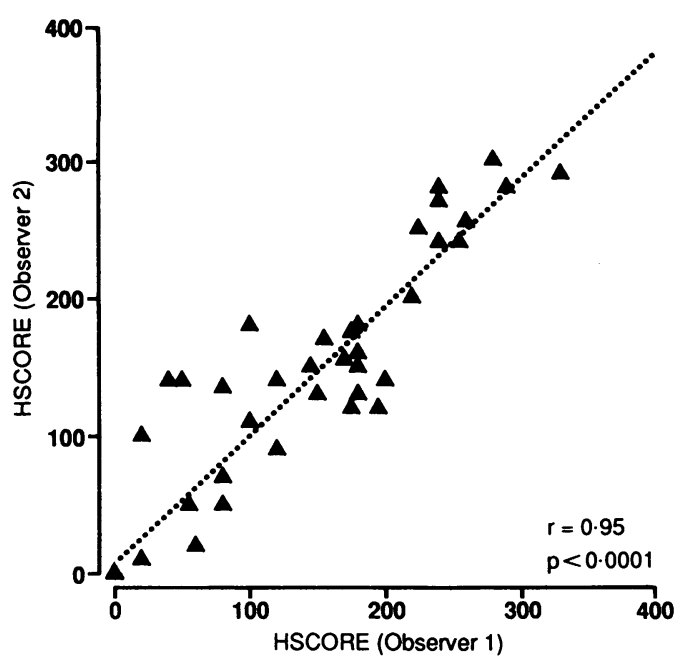

Figure 3 Interobserver variation.

frozen tissue sections. Various enzyme treatments unmask or restore the oestrogen receptor antigen in formalin fixed and paraffin wax

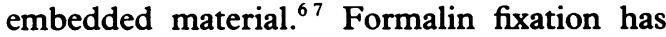
the advantage of better cytomorphological preservation, larger sections available for assessment, and retrospective analysis.

The overall sensitivity and specificity in the present study was $88 \%$ and $93 \%$, respectively. This agrees with the findings of previous studies. ${ }^{8}$ The ER-ICA method produced one false-positive result. This was a section from a breast showing fibroadenomatosis; the EIA value was $6 \mathrm{fmol} / \mathrm{mg}$ and the HSCORE value was 30 . We think that this discrepancy could have been due to heterogeneity of oestrogen receptor staining, low cellularity of the sample, or simply sampling error rather than unspecific staining by the ICA method. We had five falsenegative ER-ICA cases. The reason for the disagreement in three of these cases (EIA values of 11,16 , and $29 \mathrm{fmol} / \mathrm{mg}$ ) could, in our opinion, have been due to heterogeneity of oestrogen receptor expression, but as in the two last cases (EIA values of 56 and $441 \mathrm{fmol} / \mathrm{mg}$ ) we cannot rule out the possibility that the ERICA method applied to paraffin wax sections has a reduced sensitivity due to fixation or proteolytic activity of enzymes used in the pretreatment of the slides. Unmasking of antigens in paraffin wax sections by the use of enzymes is a well established technique ${ }^{10}$; but prolonged exposure to proteolytic enzymes will unvariably lead to massive degradation of the tissue. We found that the morphology of mammary tissue was more resistant to the action of

Comparison of ER-EIA with ER-ICA on paraffin wax sections

\begin{tabular}{llll}
\hline & \multicolumn{2}{l}{$E R-I C A$} \\
\cline { 2 - 4 } ER-EIA & Negative & Positive & Total \\
\hline$<10 \mathrm{fmol} / \mathrm{mg}$ & 14 & 1 & 15 \\
$>10 \mathrm{fmol} / \mathrm{mg}$ & 5 & $37^{\star}$ & 42 \\
Total & 19 & 38 & 57
\end{tabular}

Sensitivity: 37 of $42=88 \%$, specificity: 14 of $15=93 \%$. *One case of poorly differentiated (grade 3 ) endometrial adenocarcinoma with EIA $=258 \mathrm{fmol} / \mathrm{mg}$ was ER-ICA negative, but adjacent hyperplastic glandular elements were moderately positive; HSCORE $=165$. protease, and required 10 minutes of pronase plus 30 minutes of DNase incubation for optimal ER-ICA staining. Sections from endometrial carcinomas showed optimal ERICA staining with five minutes of pronase plus 30 minutes of DNase. Prolongation of pronase incubation for more than five minutes resulted in an increasing loss of morphological details and reduced ER-ICA staining intensity. The reason for this tissue specific tolerance of protease digestion is not fully understood, but may in part be due to the amount of connective tissue in the sections. In addition to the above mentioned factors, avascularisation and delayed or inadequate fixation resulting in autolytic proteolysis is known to destroy antigenic determinants, but such factors are difficult to assess retrospectively.

The problem of ensuring a representative sample is one of the major drawbacks of biochemical methods. In one case of poorly differentiated (grade 3 ) endometrial adenocarcinoma assigned an EIA value of $258 \mathrm{fmol} / \mathrm{mg}$, the ICA technique showed an oestrogen receptor negative tumour, with adjacent abundant hyperplastic glandular elements given a HSCORE of 165. This pinpoints the importance of recognising oestrogen receptor positivity at a cellular level. It may be that cellular localisation of oestrogen receptor positivity and assessment of oestrogen receptor staining heterogeneity, both of which are possible by the ICA method, can contribute to better prediction of hormone responsiveness in oestrogen receptor positive breast and endometrial carcinomas. ${ }^{11}$

The intra- and interobserver variation of the HSCORE was excellent, with $r$ values of 0.97 $(\mathrm{p}<0.0001)$ and $0.95(\mathrm{p}<0.0001)$, respectively. This high degree of reproducibility compares favourably with what is found for histological grading ${ }^{12}$ and probably reflects the fact that immunohistochemical staining is a simple system, with only one variable. On the other hand, while the question of whether staining is positive or not is fairly easy to settle, it is more difficult to grade the intensity of staining and estimate the percentage of stained

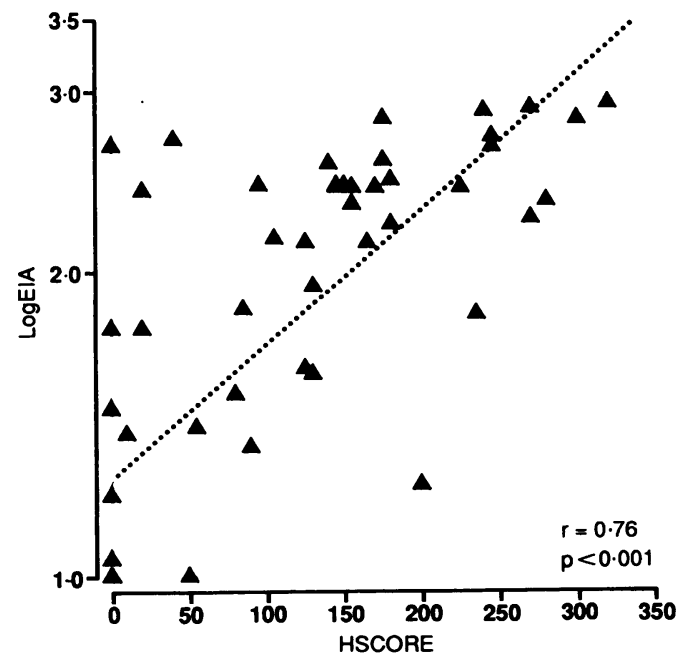

Figure 4 Correlation between oestrogen receptor ICA (HSCORE) and log oestrogen receptor EIA. 
cells. This can therefore only be a semiquantitative measurement, and complete agreement with a quantitative measurement such as the ER-EIA is hardly to be expected. Until suitable computer programs for image analysis have been developed, however, this seems the best way to assess oestrogen receptor content in tissue sections.

We believe that the method described in this study concerning ER-ICA on formalin fixed and paraffin wax embedded material, using enzymatic pretreatment of the sections and the HSCORE evaluation method for immunohistochemical staining developed by McCarthy et $a l,{ }^{8}$ could be an important supplement to quantitative biochemical methods for oestrogen receptor determination. The most important features of this method are its ability to ensure the representative quality of the sample, and to correct for variables such as heterogeneity and cellularity. Furthermore, the possibility of oestrogen receptor analysis in tumours and in in situ lesions that are too small for conventional analysis, is one of the most promising and important benefits of this approach.

We thank $S$ Ørnsjø for typing the manuscript. This work was supported by grants from the Norwegian Cancer Society, where
T A Aasmundstad is a research fellow, and from Kreftfondet, Regionsykehuset i Trondheim.

1 Williams MR, Todd JH, Ellis IO, et al. Oestrogen receptors in primary and advanced breast cancer: an eight year review of 704 cases. $\mathrm{Br} J$ Cancer 1987;55:67-73.

2 Shek LL, Godolphin W. Survival with breast cancer: the importance of oestrogen receptor quantity. Eur $J$ Cancer Clin Oncol 1989;25:243-50.

3 Kauppila A. Oestrogen and progestin receptors as prognostic indicators in endometrial cancer. Acta Oncol 1989; 28:561-6.

4 Parl FF. Oestrogen receptor determination in human breast cancer. In: Stafinini M, Gorstein F, Fink LM, eds. Progressing clinical pathology. Vol IX. Orlando, Florida: Grune \& Stratton, 1984:155-72.

5 Craig Allred D, Bustamante MA, Daniel CO, Gaskill HV, Cruz AB Jr. Immunocytochemical analysis of oestrogen receptors in human breast carcinomas. Arch Surg 1990; 125:107-13.

6 Shintaku IP, Said JW. Detection of oestrogen receptors with monoclonal antibodies in routinely processed formalinfixed paraffin sections of breast carcinoma. Am J Clin Pathol 1987;87:161-7.

7 Cheng L, Binder SW, Fu YS, Lewin KJ. Demonstration of oestrogen receptors by monoclonal antibody in formalinfixed breast tumors. Lab Invest 1988;58:346-53.

8 McCarty KS Jr, Miller LS, Cox EB, Konrath J, McCarty KS Sr. Oestrogen receptor analysis. Arch Pathol Lab Med 1985;109:716-21.

9 Greene GL, Nolan C, Engler JP, Jensen EV. Monoclonal antibodies to human oestrogen receptor. Proc Natl Acad Sci USA 1980;77:5115-9.

10 Curran RC, Gregory J. The unmasking of antigens in paraffin sections of tissue trypsin. Experimentia 1977 ; 33:1400-1.

11 Pertschuk LP, Kim DS, Nayer K, et al. Immunocytochemical oestrogen and progestin receptor assays in breast cancer with monoclonal antibodies. Cancer 1990;66: 1663-70.

12 Elston CW. Grading of invasive carcinoma of the breast. In: Anderson TS, Page DL, eds. Diagnostic histopathology of the breast. Edinburgh: Churchill Livingstone, 1987: 300-11. 